\title{
Perioperative anesthetic considerations in patients with pulmonary hypertension undergoing non-cardiac and non-obstetric surgeries
}

\author{
Jong Sik Seo', Keum Young So ${ }^{2,3}$, Sang Hun $\mathrm{Kim}^{2,3}$ \\ ${ }^{1}$ Department of Medicine, Graduate School of Chosun University, ${ }^{2}$ Department of Anesthesiology and Pain Medicine, School of \\ Medicine, Chosun University, ${ }^{3}$ Department of Anesthesiology and Pain Medicine, Chosun University Hospital, Gwangju, Korea
}

Received May 31, 2019

Accepted June 9, 2019

Corresponding author

Sang Hun Kim

Department of Anesthesiology and

Pain Medicine, School of Medicine,

Chosun University, 309, Pilmun-

daero, Dong-gu, Gwangju 61452,

Korea

Tel: +82-62-220-3223

Fax: +82-62-223-2333

E-mail: ksh3223@chosun.ac.kr

ORCID:

https://orcid.org/0000-0003-3869-9470

\begin{abstract}
The management of pulmonary hypertension $(\mathrm{PH})$, one of the most important perioperative risk factors, is innately challenging to anesthesiologists owing to its life-threatening consequences. The number of patients with PH has increased because of the development of more effective treatment and advanced hemodynamic monitoring, which consequently result in a longer life-expectancy. By understanding the associated risk factors, utilizing therapies based on $\mathrm{PH}$ classification, and performing careful perioperative anesthetic planning and management, we can safely perform elective surgeries or procedures on these patients. In particular, the perioperative management of patients with $\mathrm{PH}$ requires a multidisciplinary approach, which is aimed at carefully optimizing hemodynamics, minimizing risk factors, and aggressively treating complications. This review provides an evidence-based overview of the definition and classification of and treatments for $\mathrm{PH}$, while also focusing on the perioperative management and treatment of patients with $\mathrm{PH}$ in non-cardiac and non-obstetric settings.
\end{abstract}

Keywords: Anesthesia; Hypertension; Pulmonary; Perioperative care/methods

\section{INTRODUCTION}

Pulmonary hypertension $(\mathrm{PH})$ is one of the most important perioperative risk factors, which poses a significant challenge to anesthesiologists. The number of patients with $\mathrm{PH}$ has increased because of the increased understanding of the disease, better diagnostic techniques, and improvement in the functional status owing to the development of more effective treatments and advanced hemodynamic monitoring, which consequently result in a longer life-expectancy [1]. Therefore, we have been encountering increasing numbers of patients with this complex condition presenting for non-cardiac and non-obstetric surgeries, despite having a considerably increased risk of morbidity and mortality.

The perioperative management of patients with $\mathrm{PH}$ requires a multidisciplinary approach, which is aimed at carefully optimizing hemodynamics (right ventricular [RV] preload, afterload, and contractility), minimizing risk factors, and aggressively treating complications [2]. However, there is lack of comprehensive evidence-based guidelines, applicable risk assessment, and perioperative management of patients with $\mathrm{PH}$ with respect to anesthetic management [3,4]. In fact, most recommendations are based on expert opinions or case series rather than well-designed random- 
ized controlled trials.

This review provides an evidence-based overview of the definition and classification of and treatments for $\mathrm{PH}$, while also focusing on the perioperative management and treatment of patients with $\mathrm{PH}$ in non-cardiac and non-obstetric settings.

\section{DEFINITION}

The hemodynamic definition of $\mathrm{PH}$ is a resting mean pulmonary arterial pressure (mPAP) $\geq 25 \mathrm{mmHg}$, and it is $\geq 30$ $\mathrm{mmHg}$ during exercise [5,6]. Borderline $\mathrm{PH}$ is defined as a mPAP between 20 and $24 \mathrm{mmHg}$ [1].

\section{CLASSIFICATIONS}

$\mathrm{PH}$ is clinically classified into five categories on the basis of the similarities in pathophysiology and therapeutic methods [7-9]. The most recently defined categories are pulmonary arterial hypertension (PAH) (Group I), $\mathrm{PH}$ due to left heart disease (Group II), PH due to chronic lung disease and/or hypoxia (Group III), PH due to pulmonary artery obstructions (Group IV), and PH due to unclear and/or multifactorial mechanisms (Group V) (Table 1) [7,10].

$\mathrm{PH}$ can also be defined on the basis of the hemodynamic states as follows (Table 2): precapillary $\mathrm{PH}$ is $\mathrm{mPAP} \geq$ $25 \mathrm{mmHg}$, pulmonary artery wedge pressure (PAWP) $\leq 15$ $\mathrm{mmHg}$, and pulmonary vascular resistance (PVR) $\geq 3$ Wood units (WUs) (groups I, III, IV, and V); isolated postcapillary $\mathrm{PH}$ is $\mathrm{mPAP} \geq 25 \mathrm{mmHg}$, PAWP $>15 \mathrm{mmHg}$, and PVR $\leq 3 \mathrm{WU}$ (groups II and V); and combined precapillary and postcapillary $\mathrm{PH}$ is $\mathrm{mPAP} \geq 25 \mathrm{mmHg}$, PAWP $>15 \mathrm{mmHg}$, and PVR $\geq$
Table 1. Comprehensive clinical classification of pulmonary hypertension [10]

Type 1: Pulmonary arterial hypertension
Idiopathic
Hereditary
Drug- and toxin-induced
Associated with
Connective tissue disease
Human immunodeficiency virus infection
Portal hypertension
Congenital heart diseases
Schistosomiasis
Pulmonary veno-occlusive disease and/or pulmonary capillary
hemangiomatosis
Persistent pulmonary hypertension of the newborn

Type 2: Pulmonary hypertension due to left heart disease

Left ventricular systolic dysfunction

Left ventricular diastolic dysfunction

Valvular disease

Congenital/acquired left heart inflow/outflow tract obstruction and cardiomyopathies

Type 3: Pulmonary hypertension due to lung diseases and/or hypoxia Chronic obstructive pulmonary disease Interstitial lung disease

Other pulmonary diseases with mixed restrictive and obstructive patterns

Sleep-disordered breathing

Alveolar hypoventilation disorders

Chronic exposure to high altitude

Developmental lung diseases

Type 4: Chronic thromboembolic pulmonary hypertension and other pulmonary artery obstructions

Type 5: Pulmonary hypertension with unclear multifactorial mechanisms Hematological disorders: Chronic hemolytic anemia, myeloproliferative disorders, and splenectomy

Systemic disorders: Sarcoidosis, pulmonary histiocytosis, and lymphangioleiomyomatosis

Metabolic disorders: Glycogen storage disease, Gaucher disease, and thyroid disorders

Others: Tumoral obstruction, fibrosing mediastinitis, chronic renal failure, and segmental pulmonary hypertension

Table 2. Hemodynamic definitions of pulmonary hypertension at resting [10]

\begin{tabular}{|c|c|c|}
\hline Definition & Characteristic & Clinical group(s) \\
\hline $\mathrm{PH}$ & $\mathrm{mPAP} \geq 25 \mathrm{mmHg}$ & All \\
\hline Precapillary PH & $\begin{array}{l}\mathrm{mPAP} \geq 25 \mathrm{mmHg} \\
\mathrm{PAWP} \leq 15 \mathrm{mmHg}\end{array}$ & $\begin{array}{l}\text { 1. Pulmonary arterial hypertension } \\
\text { 3. } \mathrm{PH} \text { due to lung diseases } \\
\text { 4. Chronic thromboembolic } \mathrm{PH} \\
\text { 5. } \mathrm{PH} \text { with unclear and/or multifactorial mechanisms }\end{array}$ \\
\hline Postcapillary PH & $\begin{array}{l}\mathrm{mPAP} \geq 25 \mathrm{mmHg} \\
P A W P>15 \mathrm{mmHg}\end{array}$ & $\begin{array}{l}\text { 2. } \mathrm{PH} \text { due to left heart disease } \\
\text { 5. } \mathrm{PH} \text { with unclear and/or multifactorial mechanisms }\end{array}$ \\
\hline Isolated postcapillary PH & $\mathrm{DPG}<7 \mathrm{mmHg}$ and/or $\mathrm{PVR} \leq 3 \mathrm{WU}$ & \\
\hline Combined precapillary and postcapillary PH & $\mathrm{DPG} \geq 7 \mathrm{mmHg}$ and/or PVR $>3 \mathrm{WU}$ & \\
\hline
\end{tabular}

PH: pulmonary hypertension, mPAP: mean pulmonary arterial pressure, PAWP: pulmonary arterial wedge pressure, DPG: diastolic pressure gradient (diastolic PAP - mean PAWP), PVR: pulmonary vascular resistance, WU: Wood units (Wood units are preferred to dynes.s. $\mathrm{cm}^{-5}$ ). 
3 WU (groups II and V) [7,10].

\section{GENERAL TREATMENTS}

$\mathrm{PH}$ is known to be related to reduced nitric oxide (NO) and prostacyclin synthesis as well as to increased thromboxane production. From a pathophysiological perspective, all patients with $\mathrm{PH}$ are in a state of reduced NO bioavailability, which has antiproliferative as well as vasodilatory properties, and increased phosphodiesterase- 5 (PDE-5) expression in the endothelial smooth muscle cells and RV [11,12].

However, the treatment modalities differ according to the PH groups [13]. Group I usually requires anticoagulation, diuretics, oxygen therapy, calcium channel blockers, and digoxin. According to the functional status and objective tests like the 6-m walking distance (6MWD), if patients have a low risk, i.e., New York Heart Association (NYHA) functional classes I-III, they may be treated using inhaled prostacyclins, oral endothelin receptor antagonists (ERAs; bosentan, ambrisentan, and macitentan), oral PDE -5 inhibitors (sildenafil and tadalafil), or other newer drugs like riociguat (a new class of soluble guanylate cyclase stimulators) and selexipag (an oral selective prostacyclin receptor agonist). If patients have a high risk, i.e., NYHA functional classes III or IV, they should be treated with intravenous or subcutaneous prostacyclins. These PH-targeting drug therapies are only licensed for patients in Group I [4]. Moreover, in the perioperative period, anesthesiologists usually encounter more patients belonging to Groups II and III (PH types 2 and 3) than to Group I. In these patients, the management of PH usually focuses on the direct correction of the main or underlying disease via surgical or pharmaceutical therapy. Patients in Group II are managed using therapies for left heart failure. Unfortunately, pulmonary vasodilator therapy may deteriorate pulmonary edema by increasing the blood flow and elevating the left-sided filling pressures. ERAs and prostacyclins should not be used except for some patients with intrinsic pulmonary vascular disease, who may potentially benefit from the use of PDE- 5 inhibitors. Patients in Group III are managed via the direct correction of the underlying lung disease, and pulmonary vasodilator therapy is not beneficial and may worsen ventilation-perfusion matching. Patients in Group IV can be potentially cured using thromboendarterectomy. Pulmonary vasodilator therapy may be used in such patients who are not candidates for surgery. For patients in Group V, the underlying disease can be directly managed.

\section{GENERAL OUTCOMES}

The elevated PAP results in an increased PVR, cardiac output (CO), and/or PAWP, which is consequently associated with the development of right heart failure as the major concern with $\mathrm{PH}$. The RV in patients with chronic $\mathrm{PH}$ gradually dilates and fails, leading to a reduced RV stroke volume, RV ischemia, decreased left ventricle (LV) preload and $\mathrm{CO}$, and hypotension. In patients with acute $\mathrm{PH}$, the increased PAP can result in rapid RV failure because the RV is a low-pressure system.

Postoperative morbidity and mortality is $4-24 \%$ in patients with $\mathrm{PH}$, who are high-risk candidates based on the severity of disease and the surgical procedure [14]. In particular, the mortality and morbidity for non-cardiac surgery ranged from $1-18 \%$ and $14-42 \%$, respectively [4]. In addition, the cost-related outcomes are influenced by the presence of $\mathrm{PH}$, which is related to a significantly longer length of stay in the intensive care unit (ICU) and hospital, as well as a 2.4-fold increased risk of 1-month re-admission [15].

Patients with $\mathrm{PH}$ also have some common risk factors (procedure-related and patient-related factors). They are major surgery, emergency surgery, surgery duration $>3 \mathrm{~h}$, high American Society of Anesthesiologists class, vasopressor use, and concomitant cardiovascular disease [13,15-20]. In addition, hemodynamics (such as a right atrial pressure $\geq 7 \mathrm{mmHg}$ ), NYHA functional class (>II), and 6MWD (<300 $\mathrm{m}$ ) were included as common risk factors, even though they were inconsistently observed $[13,15,16]$. In particular, the mPAP was associated with perioperative morbidity, and patients with isolated postcapillary PH had lesser morbidity and mortality than did patients with precapillary $\mathrm{PH}$ or combined precapillary and postcapillary $\mathrm{PH}$ [15].

\section{PERIOPERATIVE ANESTHETIC MANAGEMENT}

\section{Preoperative evaluation and management}

Thorough medical history taking (symptoms and signs) and physical examination, assessment of the patient's functional state, and determination of PH severity and suitable 
surgical procedure are very important in a preoperative evaluation. These should be performed considering all potential factors, such as $\mathrm{PH}$ etiology, $\mathrm{PH}$ severity, type of surgery, urgency of the procedure, comorbid conditions, functional state, and medication optimization.

Generally, the primary investigations include preoperative routine laboratory evaluations, echocardiography, pulmonary function tests including blood gas analysis, and right heart catheterization. In the laboratory evaluation, pro-brain natriuretic peptide level is recommended as a predictor of postoperative cardiac mortality after non-cardiac surgery [21]. Overall echocardiography should also be evaluated. The right atrial enlargement surface $\left(>27 \mathrm{~mm}^{2}\right)$, reduced tricuspid annular plane systolic excursion, and pericardial effusion are poor prognostic predictors [22]. However, we should consider that the mPAP calculated using echocardiography is often underestimated. Therefore, right heart catheterization is required for mPAP measurement and for differentiating between precapillary and postcapillary $\mathrm{PH}$, but it should be performed very cautiously to avoid related complications [13].

Unfortunately, we do not have strong supporting evidence on any specific preoperative test to predict the postoperative outcomes of non-cardiac surgery. In case of inadequately categorized $\mathrm{PH}$, we must postpone elective surgery and should consider consultation with experts in cardiology, respiratory medicine, and imaging for disease classification, assessment of functional status/exercise capacity (6MWD), and additional hemodynamic measurements. In case of known and well-categorized $\mathrm{PH}$, we should evaluate the optimization of medical therapies, functional status/6MWD, and hemodynamics. However, we should remember that a procedure or surgery may be delayed because of these evaluations and for the optimization of $\mathrm{PH}$ treatment.

We need to perform optimal individualized medication planning. All PH medications, such as pulmonary vasodilators (intravenous or inhaled), digoxin, diuretics, calcium channel blockers, ERAs, and PDE-5 inhibitors, as well as oxygen therapy, should be continued until the day of surgery $[13,14,23,24]$. This is because the abrupt discontinuation of pulmonary vasodilators can result in rebound $\mathrm{PH}$ and hemodynamic instability, and can be life-threatening. However, preoperative oral pulmonary vasodilator therapy may have to be converted to intravenous or inhaled therapy owing to nothing-by-mouth status or the hospital's formulary restrictions. Warfarin should be bridged to low-molecular-weight/unfractionated heparin before surgery [13] If $\mathrm{PH}$ is diagnosed immediately before an urgent surgery, treatment with PDE- 5 inhibitors and L-arginine should be started as soon as possible [14].

A recent study suggested the formation of a comprehensive multidisciplinary team of participating anesthesiologists, surgeons, and PH experts as an important tool for perioperative PH management [25]. Such a team could focus on designing individualized operative plans for each patient and on effectively mitigating perioperative morbidity and mortality. This team would perform complete disease phenotyping, medication review and optimization 2 weeks before surgery, clinical examination, 6MWD with/without right heart catheterization within 2 weeks of surgical planning, and discuss ways to minimize operative time [3]. Both surgical length and type have an impact on hemodynamics and will influence anesthesia planning, which should be performed to minimize the risk for each individual patient. In some cases, a more invasive approach may be preferred, such as open surgery rather than laparoscopic surgery, considering the effects of pneumoperitoneum with high abdominal insufflation pressures (hypoxia, hypercarbia, and emboli) on PVR and RV preload/afterload [4,26,27].

In addition, this team should address several major questions [3]. 1) Do the benefits of the surgery outweigh the PH-associated risks? 2) Is the patient medically optimized? 3) What is the best perioperative PH medication plan? 4) Which type of procedure or surgery is better to mitigate the PH-associated risk? 5) Should the procedure or surgery be moved from its usual location? 6) Who is the best anesthesiologist to deal with the patient with $\mathrm{PH}$ ? 7) Which is the optimal postoperative care location? 8) Is extracorporeal membrane oxygenation (ECMO) required (this decision mandates discussion prior to the surgery and not on an emergency basis)? 9) Is additional expert input required?

\section{Intraoperative management}

Intraoperative management should focus on the prevention of PH crisis and RV failure, aggressive control of $\mathrm{PH}$ triggers, adequate systemic perfusion and RV preload, and optimal contractility [24]. An individualized plan based on the pathophysiology and comorbidities is very important to 
avoid events causing pulmonary vasoconstriction or systemic hypotension, as well as to maintain RV function.

Various anesthetic agents can be used to accomplish these hemodynamic goals, even though there is no proven superiority [28]. For patients with PH, it is best to select options that can minimize the intraoperative increase in PVR and depression of myocardial function with adequate anesthesia and analgesia.

Traditionally, volatile anesthetics have been known to attenuate hypoxic pulmonary vasoconstriction, thereby decreasing ventilation-perfusion matching [29]. In addition, volatile anesthetics can be used up to 1 minimum alveolar concentration without any negative effect on the pulmonary vasculature [13]. Isoflurane and enflurane have effects on pulmonary vasodilation and endothelium-dependent relaxation inhibition but no effects on the baseline pulmonary circulation tone. However, desflurane potentiates the pulmonary vasoconstriction response [29]. Sevoflurane also has a pulmonary vasodilation effect like isoflurane, but it does not inhibit endothelium-dependent relaxation [29]. Accordingly, isoflurane and sevoflurane are accepted for anesthetic induction and maintenance, and sevoflurane may be preferable to isoflurane in patients with $\mathrm{PH}$. However, we should consider that volatile agents can lead to dose-dependent problematic depression of RV contractility and the reduction of systemic vascular resistance (SVR). Nitrous oxide should be avoided, because it significantly elevates PVR despite having little effect on pulmonary hemodynamics [29].

Opioids have a minimal effect on the pulmonary vasculature, and they can be used to attenuate the noxious stimulus-related pulmonary vascular response $[14,30]$. However, opioid-induced bradycardia may cause an undesired decrease in the $\mathrm{CO}$, even though it can be easily controlled with atropine or another chronotropic drug.

We can use benzodiazepines, which have minimal hemodynamic effects and cause non-significant respiratory depression, but they should be used carefully in patients with PH and upper airway disease [29]. Although thiopental does not affect PVR, it is less desirable because it can induce myocardial depression (reduced RV contractility) and systemic hypotension (reduced SVR) [4,29]. Propofol has been known to trigger an increase in either PVR or pulmonary vasodilation [14] and to decrease SVR significantly and cardiac contractility mildly [29]. In patients with cardiac shunt and fixed, elevated PVR, propofol may aggravate oxygen desaturation because of the decreased SVR caused by the augmentation of the right-to-left shunt [29]. However, while propofol has no effect on NO-induced pulmonary vasodilatation and the basal pulmonary vascular tone, it can increase the pulmonary response to vasoconstrictors [14]. Etomidate can also be used in patients with RV dysfunction, but it causes a mild elevation of PVR [4,29]. The use of ketamine in patients with $\mathrm{PH}$ is controversial, and we cannot ignore its effect on increasing PVR or PAP. Ketamine-related catecholamine release, which constricts the pulmonary vasculature, can be minimized by the co-administration of benzodiazepines or pulmonary vasodilating drugs, or by enriching the inspiratory oxygen concentration $\left(\mathrm{FiO}_{2}\right)$ [31]. If ketamine does not increase PVR, it offers several potential benefits (preservation of coronary blood flow and maintenance of the ratio of pulmonary to systemic blood flow) by maintaining blood pressure and SVR [29]. In addition, dexmedetomidine, an alpha-2 agonist, may have beneficial effects on central sympathetic outflow reduction, sedation, and analgesia in patients with $\mathrm{PH}$ [24].

No single anesthetic agent has been shown to be ideal for patients with $\mathrm{PH}$, and many different techniques can be safely employed. After premedication with midazolam, anesthetic induction and maintenance may be performed with the co-administration of benzodiazepines, opioids, ketamine, a small dose of propofol, and/or a low concentration of volatile anesthetics (such as isoflurane and sevoflurane) [29].

Despite airway and ventilatory problems during sedation or anesthesia, the incidence of complications in patients with $\mathrm{PH}$ undergoing non-cardiac surgery are independent of the method of airway management [29]. Laryngoscopy and intubation are known to cause pulmonary hypertensive crisis and even death in patients with severe PH [32,33]; therefore, careful airway management is required to prevent these critical complications by administering adequate anesthesia and analgesia or by avoiding intubation when possible. Extubation should be considered when patients have appropriate ventilation on minimal ventilator settings with an $\mathrm{FiO}_{2}$ ratio $\leq 0.4$ [24]. Furthermore, deep extubation or early extubation can decrease the exposure to noxious airway stimulation [29]. End-tidal $\mathrm{CO}_{2}$ should be monitored for rapid intervention in patients under sedation without airway 
devices [34].

In view of adequate oxygenation and controlled ventilation, general anesthesia is preferred in patients with $\mathrm{PH}$ [13]. Nevertheless, general anesthesia may expose the patient to apnea and hypoventilation, hypoxemia, hypothermia, hypotension, intense sympathetic stimulation, rapid fluid shift, and a change in cardiac preload [35]. In addition, RV afterload and pulmonary hypertensive crisis may be significantly increased by positive pressure ventilation with/without positive end-expiratory pressure (PEEP) [4]. However, general anesthesia also has beneficial effects such as reducing the RV ischemia due to anesthetic-related hypotension and the mechanical ventilation-induced elevation of PVR [6]. Therefore, perioperative hemodynamic control is suggested to maintain a systolic pressure $>90 \mathrm{mmHg}$, mean arterial pressure $>65 \mathrm{mmHg}, \mathrm{mPAP}<35$, PVR/SVR ratio $<0.5$, and cardiac index $>2.2 \mathrm{~L} / \mathrm{min} / \mathrm{m}^{2}$ [4]. Epidural anesthesia using a low dose and slow titration is also well tolerated, but spinal anesthesia should be avoided [24]. Regional anesthesia also has advantages such as the avoidance of elevated pulmonary arterial pressures caused by mechanical ventilation and a non-significant influence on PVR and oxygenation [36,37]. It can be used for postoperative analgesic therapy. However, regional anesthesia can decrease SVR, and this should be carefully considered in patients with advanced $\mathrm{PH}$ who cannot lie down for a long time, as well as in patients receiving anticoagulants. Hence, in patients with $\mathrm{PH}$, a balanced technique involving the use of higher doses of opioids and low-dose volatile anesthetics, or a combined anesthesia technique with volatile anesthetics and regional or neuraxial anesthesia, is preferable [38]. However, histamine-releasing neuromuscular blockers, such as atracurium and cisatracurium, should be avoided because they cause an increase in PVR [6]. Rocuronium and vecuronium are also preferable as neuromuscular blockers [29].

The requirement for intraoperative monitoring is mainly dictated by the severity of $\mathrm{PH}$, comorbidities, exercise tolerance, and surgical procedure. In addition to standard monitoring, invasive arterial blood pressure and central venous pressure monitoring are required to obtain information on immediate hemodynamic changes and early warning signs of cardiovascular decompensation [13]. Temperature should also be monitored [13], and air-forced warming blankets as well as intravenous fluid warmers should be applied, if available, to prevent hypothermia. Pulmonary artery catheterization has a relatively high complication rate (transient ventricular arrhythmia or pulmonary artery rupture) and should be performed much less frequently because of its inconsistent results related to improved outcomes [13,39,40]. Therefore, we should carefully weigh the risks and benefits of this procedure. Transesophageal echocardiography can provide direct visualization of the cardiac anatomy and functional status, especially pulmonary arterial pressures, valvular regurgitation, $\mathrm{CO}$, and regional wall motion abnormality [13]. Central venous oxygen saturation monitoring can also be used as a marker of global tissue perfusion [13]. Stroke volume variability is helpful for intraoperative fluid management as an appropriate method for evaluating volume responsiveness [38,41].

The most important requirement for the management of pulmonary hypertensive crisis (intraoperative increased PAP) is to avoid anything that could increase RV afterload or decrease RV contractility $[38,42]$. Hence, we should try to treat and prevent hypoxia, hypoxemia, hypercarbia (due to sedation, analgesia, poor mask seal, and delayed intubation), acidosis (secondary to hypovolemia, infection, and decreased (C), hypothermia, atelectasis, hyperinflation (due to inadequate tidal volume or PEEP), and catecholamine release (due to pain, inadequate anesthesia, anxiety, and histamine release drugs) [3].

High $\mathrm{FiO}_{2}$ (0.6-1.0) should be used, and a tidal volume of 6-8 $\mathrm{mL} / \mathrm{kg}$ ideal body weight is recommended to set the peak pressures as low as possible to avoid alveolar overinflation [38]. The respiratory rate should be controlled to maintain a partial pressure of $\mathrm{CO}_{2}$ of $30-35 \mathrm{mmHg}$ [38]. Large-volume fluid infusion, especially of cold fluids, should be avoided because it can result in hypothermia and increase RV oxygen consumption. Therefore, fluid infusion should be restricted as far as possible, and when required, the fluid should be warmed using fluid warmers.

Permissive hypotension is not applicable to patients with high-risk PH. Pure alpha agonists such as phenylephrine and clonidine should be avoided, and norepinephrine or vasopressin is preferable as a vasopressor to maintain blood pressure [43-40]. Indeed, low-dose vasopressin (0.04 U/min) and dobutamine $(2-5 \mu \mathrm{g} / \mathrm{kg} / \mathrm{min})$ restore coronary blood flow to the RV by increasing SVR [3,47]. However, dobutamine, being an inotrope, exacerbates systemic hypotension 
due to anesthetic (inhaled or intravenous)-induced systemic vasodilation [3]. Therefore, norepinephrine, which has both vasopressor and inotropic properties, is frequently preferred for intraoperative administration in patients with acute RV failure due to $\mathrm{PH}[26,48]$.

Intravenous vasodilators such as milrinone $(25-50 \mu \mathrm{g} / \mathrm{kg}$ bolus, followed by $0.5-0.75 \mu \mathrm{g} / \mathrm{kg} / \mathrm{min}$ ) and enoximone can be used [13]. Prostacyclin (4-10 ng/ $\mathrm{kg} / \mathrm{min}$ ), iloprost (1-3 $\mathrm{ng} / \mathrm{kg} / \mathrm{min})$, sildenafil $(0.25-0.5 \mathrm{mg} / \mathrm{kg}$, every $4-8 \mathrm{~h}$ per oral, or $1.6 \mathrm{mg} / \mathrm{kg} /$ day intravenously), nitroglycerine $(2-10 \mu \mathrm{g} /$ $\mathrm{kg} / \mathrm{min})$, or sodium nitroprusside $(0.2-0.3 \mu \mathrm{g} / \mathrm{kg} / \mathrm{min})$ can also be used for PH treatment [13]. Calcium channel blockers, such as diltiazem, nifedipine, and amlodipine, may be harmful to patients experiencing pulmonary hypertensive crisis and those with non-reactive, fixed PH because the decreased SVR and CO can result in myocardial ischemia due to decreased coronary blood flow [29].

Inhaled NO (5-40 ppm continuously), prostacyclin (25$50 \mu \mathrm{g}$, nebulized over $15 \mathrm{~min}$, every hour), iloprost (5-10 $\mathrm{mg}$, nebulized over $10 \mathrm{~min}$, every 2-4 h), milrinone (2-5 mg, for 10-15 $\mathrm{min}$ ), or epoprostenol (10-50 $\mathrm{ng} / \mathrm{kg} / \mathrm{min}$ continuously) can be administered to quickly lower RV afterload in patients with severe or acute decompensated PH [13,26]. Epoprostenol infusion should be performed uninterrupted because of the extremely short half-life of the drug [29]. These pulmonary vasodilators should be carefully used in patients with $\mathrm{PH}$ because of downstream obstructions, such as pulmonary vein stenosis, pulmonary veno-occlusive disease, and left atrial hypertension, because their use prior to the relief of the obstruction can lead to acute, life-threatening pulmonary edema [29]. Studies recommend that PAP be controlled within $15 \%$ fluctuation from the initial values measured during preoperative evaluation [14].

\section{Postoperative management}

Patients with severe compensated PH might undergo minor surgery on an outpatient basis, while those undergoing major surgery should be cared for in an ICU by staff experienced in managing postoperative $\mathrm{PH}[3,16,49]$. However, the general principle for postoperative management is that the patient should be fully monitored in the ICU and pressures should be maintained with the judicious use of vasopressors and inotropes, along with blood volume replacement to maintain a hemoglobin level $\geq 10 \mathrm{~g} / \mathrm{dL}$ if needed [13].
However, we should consider that volume loading may paradoxically lead to a reduction in LV preload and worsen hypotension [24]. All precautions should be taken to avoid hypoxemia, hypotension, and hypovolemia. However, if prior therapies fail, we can consider mechanical support such as ECMO [24]. Moreover, mechanical support should be provided before intubation to avoid hemodynamic instability.

The plan for postoperative management based on the severity of $\mathrm{PH}$ and the complexity of the surgery should be established during the preoperative evaluation. The most critical complications often occur within $48 \mathrm{~h}$ after the procedure or surgery, especially in patients with precapillary $\mathrm{PH}$ or PAH [15-17]. These complications commonly develop via a progressive increase in the heightened sympathetic tone, cardiac arrhythmia, pulmonary thromboembolism, pulmonary vascular tone, acute pulmonary vasospasm, and fluid shifts [14].

Adequate postoperative analgesia should be provided with regional analgesia and non-opioid (oral or intravenous) medications [13]. Postoperative arrhythmia should be treated using amiodarone rather than $\beta$ lockers because of the former drug's intolerability; moreover, digoxin should be administered for rate control [13]. Intraoperative vasodilator therapies must be continued and slowly switched over to the preoperative regimen [13].

\section{CONCLUSIONS}

Anesthetic management is dependent on an understanding of the pathophysiology and avoidance of a pulmonary hypertensive crisis. In order to diminish risk and improve outcomes, successful perioperative anesthetic planning and management require a multidisciplinary approach, which can be applied to coordinate preoperative evaluation, intraoperative management, and postoperative care. Advanced intraoperative and postoperative monitoring, pulmonary vasodilator therapies, and adequate anesthesia and analgesia should be available and performed when necessary for patients with $\mathrm{PH}$.

\section{CONFLICT OF INTEREST}

No potential conflict of interest relevant to this article was reported. 


\section{REFERENCES}

1. Galiè N, Hoeper MM, Humbert M, Torbicki A, Vachiery JL, Barbera JA, et al. Guidelines for the diagnosis and treatment of pulmonary hypertension: the Task Force for the Diagnosis and Treatment of Pulmonary Hypertension of the European Society of Cardiology (ESC) and the European Respiratory Society (ERS), endorsed by the International Society of Heart and Lung Transplantation (ISHLT). Eur Heart J 2009;30:2493537.

2. Minai OA, Yared JP, Kaw R, Subramaniam K, Hill NS. Perioperative risk and management in patients with pulmonary hypertension. Chest 2013;144:329-40.

3. Steppan J, Diaz-Rodriguez N, Barodka VM, Nyhan D, Pullins E, Housten T, et al. Focused review of perioperative care of patients with pulmonary hypertension and proposal of a perioperative pathway. Cureus 2018;10:e2072.

4. Pilkington SA, Taboada D, Martinez G. Pulmonary hypertension and its management in patients undergoing non-cardiac surgery. Anaesthesia 2015;70:56-70.

5. Hoeper MM, Bogaard HJ, Condliffe R, Frantz R, Khanna D, Kurzyna M, et al. Definitions and diagnosis of pulmonary hypertension. J Am Coll Cardiol 2013;62(25 Suppl):D42-50.

6. Pritts CD, Pearl RG. Anesthesia for patients with pulmonary hypertension. Curr Opin Anaesthesiol 2010;23:411-6.

7. Simonneau G, Montani D, Celermajer DS, Denton CP, Gatzoulis MA, Krowka M, et al. Haemodynamic definitions and updated clinical classification of pulmonary hypertension. Eur Respir J 2019;53.

8. Kovacs G, Dumitrescu D, Barner A, Greiner S, Grünig E, Hager A, et al. Definition, clinical classification and initial diagnosis of pulmonary hypertension: updated recommendations from the Cologne Consensus Conference 2018. Int J Cardiol 2018;272S:11-9.

9. Simonneau G, Gatzoulis MA, Adatia I, Celermajer D, Denton C, Ghofrani A, et al. Updated clinical classification of pulmonary hypertension. J Am Coll Cardiol 2013;62(25 Suppl):D34-41.

10. Galiè N, Humbert M, Vachiery JL, Gibbs S, Lang I, Torbicki A, et al. 2015 ESC/ERS Guidelines for the diagnosis and treatment of pulmonary hypertension: the Joint Task Force for the Diagnosis and Treatment of Pulmonary Hypertension of the European Society of Cardiology (ESC) and the European Respiratory Society (ERS): Endorsed by: Association for European Paediatric and Congenital Cardiology (AEPC), International Society for Heart and Lung Transplantation (ISHLT). Eur Heart J 2016;37:67-119.

11. Bowers R, Cool C, Murphy RC, Tuder RM, Hopken MW, Flores SC, et al. Oxidative stress in severe pulmonary hypertension. Am J Respir Crit Care Med 2004;169:764-9.
12. Archer SL, Weir EK, Wilkins MR. Basic science of pulmonary arterial hypertension for clinicians: new concepts and experimental therapies. Circulation 2010;121:2045-66.

13. Sarkar MS, Desai PM. Pulmonary hypertension and cardiac anesthesia: anesthesiologist's perspective. Ann Card Anaesth 2018;21:116-22.

14. Blaise G, Langleben D, Hubert B. Pulmonary arterial hypertension: pathophysiology and anesthetic approach. Anesthesiology 2003;99:1415-32.

15. Kaw R, Pasupuleti V, Deshpande A, Hamieh T, Walker E, Minai OA. Pulmonary hypertension: an important predictor of outcomes in patients undergoing non-cardiac surgery. Respir Med 2011;105:619-24.

16. Meyer S, McLaughlin VV, Seyfarth HJ, Bull TM, Vizza CD, Gomberg-Maitland M, et al. Outcomes of noncardiac, nonobstetric surgery in patients with PAH: an international prospective survey. Eur Respir J 2013;41:1302-7.

17. Price LC, Montani D, Jaïs X, Dick JR, Simonneau G, Sitbon $\mathrm{O}$, et al. Noncardiothoracic nonobstetric surgery in mild-to-moderate pulmonary hypertension. Eur Respir J 2010;35:1294-302.

18. Lai HC, Lai HC, Wang KY, Lee WL, Ting CT, Liu TJ. Severe pulmonary hypertension complicates postoperative outcome of non-cardiac surgery. Br J Anaesth 2007;99:184-90.

19. Yang EI. Perioperative management of patients with pulmonary hypertension for non-cardiac surgery. Curr Rheumatol Rep 2015;17:15.

20. Memtsoudis SG, Ma Y, Chiu YL, Walz JM, Voswinckel R, Mazumdar M. Perioperative mortality in patients with pulmonary hypertension undergoing major joint replacement. Anesth Analg 2010;111:1110-6.

21. Rodseth RN, Biccard BM, Chu R, Lurati Buse GA, Thabane L, Bakhai A, et al. Postoperative B-type natriuretic peptide for prediction of major cardiac events in patients undergoing noncardiac surgery: systematic review and individual patient meta-analysis. Anesthesiology 2013;119:270-83.

22. Raymond RJ, Hinderliter AL, Willis PW, Ralph D, Caldwell EJ, Williams W, et al. Echocardiographic predictors of adverse outcomes in primary pulmonary hypertension. J Am Coll Cardiol 2002;39:1214-9.

23. Fox DL, Stream AR, Bull T. Perioperative management of the patient with pulmonary hypertension. Semin Cardiothorac Vasc Anesth 2014;18:310-8.

24. Tonelli AR, Minai OA. Saudi Guidelines on the Diagnosis and Treatment of Pulmonary Hypertension: Perioperative management in patients with pulmonary hypertension. Ann Thorac Med 2014;9(Suppl 1):S98-107.

25. Ramakrishna G, Sprung J, Ravi BS, Chandrasekaran K, McGoon MD. Impact of pulmonary hypertension on the outcomes of noncardiac surgery: predictors of perioperative 
morbidity and mortality. J Am Coll Cardiol 2005;45:1691-9.

26. Lahm T, McCaslin CA, Wozniak TC, Ghumman W, Fadl YY, Obeidat OS, et al. Medical and surgical treatment of acute right ventricular failure. J Am Coll Cardiol 2010;56:1435-46.

27. Blaney MW, Calton WC, North JH Jr. The effects of preperitoneal carbon dioxide insufflation on cardiopulmonary function in pigs. JSLS 1999;3:49-55.

28. Fox C, Kalarickal PL, Yarborough MJ, Jin JY. Perioperative management including new pharmacological vistas for patients with pulmonary hypertension for noncardiac surgery. Curr Opin Anaesthesiol 2008;21:467-72.

29. Friesen RH, Williams GD. Anesthetic management of children with pulmonary arterial hypertension. Paediatr Anaesth 2008;18:208-16.

30. Hickey PR, Hansen DD, Wessel DL, Lang P, Jonas RA, Elixson EM. Blunting of stress responses in the pulmonary circulation of infants by fentanyl. Anesth Analg 1985;64:1137-42.

31. Hatano S, Keane DM, Boggs RE, El-Naggar MA, Sadove MS. Diazepam-ketamine anaesthesia for open heart surgery a "micro-mini" drip administration technique. Can Anaesth Soc J 1976;23:648-56.

32. Höhn L, Schweizer A, Morel DR, Spiliopoulos A, Licker M. Circulatory failure after anesthesia induction in a patient with severe primary pulmonary hypertension. Anesthesiology 1999;91:1943-5.

33. Dalibon N, Moutafis M, Liu N, Michel-Cherqui M, Fischler M. Extreme pulmonary hypertension and anesthesia induction. Anesthesiology 2000;93:903-4.

34. Friesen RH, Alswang M. Changes in carbon dioxide tension and oxygen saturation during deep sedation for paediatric cardiac catheterization. Paediatr Anaesth 1996;6:15-20.

35. MacKnight B, Martinez EA, Simon BA. Anesthetic management of patients with pulmonary hypertension. Semin Cardiothorac Vasc Anesth 2008;12:91-6.

36. Jenkins J, Lynn A, Edmonds J, Barker G. Effects of mechanical ventilation on cardiopulmonary function in children after open-heart surgery. Crit Care Med 1985;13:77-80.

37. Chakravarthy M, Thimmangowda P, Krishnamurthy J, Nadiminti S, Jawali V. Thoracic epidural anesthesia in cardiac surgical patients: a prospective audit of 2,113 cases. J Cardiothorac Vasc Anesth 2005;19:44-8.

38. Seyfarth HJ, Gille J, Sablotzki A, Gerlach S, Malcharek M, Gosse A, et al. Perioperative management of patients with severe pulmonary hypertension in major orthopedic surgery: experience-based recommendations. GMS Interdiscip Plast Reconstr Surg DGPW 2015;4:Doc03.

39. Gidwani UK, Goel S. The pulmonary artery catheter in 2015: the swan and the phoenix. Cardiol Rev 2016;24:1-13.

40. Gidwani UK, Mohanty B, Chatterjee K. The pulmonary artery catheter: a critical reappraisal. Cardiol Clin 2013;31:545-65, viii.

41. Hofer CK, Senn A, Weibel L, Zollinger A. Assessment of stroke volume variation for prediction of fluid responsiveness using the modified FloTrac and PiCCOplus system. Crit Care 2008;12:R82.

42. Price LC, Wort SJ, Finney SJ, Marino PS, Brett SJ. Pulmonary vascular and right ventricular dysfunction in adult critical care: current and emerging options for management: a systematic literature review. Crit Care 2010;14:R169.

43. Wang M, Shibamoto T, Kuda Y, Tanida M, Kurata Y. Systemic vasoconstriction modulates the responses of pulmonary vasculature and airway to vasoconstrictors in anesthetized rats. Exp Lung Res 2015;41:324-34.

44. Kwak YL, Lee CS, Park YH, Hong YW. The effect of phenylephrine and norepinephrine in patients with chronic pulmonary hypertension*. Anaesthesia 2002;57:9-14.

45. Trempy GA, Nyhan DP, Murray PA. Pulmonary vasoregulation by arginine vasopressin in conscious, halothane-anesthetized, and pentobarbital-anesthetized dogs with increased vasomotor tone. Anesthesiology 1994;81:632-40.

46. Evora PR, Pearson PJ, Schaff HV. Arginine vasopressin induces endothelium-dependent vasodilatation of the pulmonary artery. V1-receptor-mediated production of nitric oxide. Chest 1993;103:1241-5.

47. Tsuneyoshi I, Onomoto M, Yonetani A, Kanmura Y. Lowdose vasopressin infusion in patients with severe vasodilatory hypotension after prolonged hemorrhage during general anesthesia. J Anesth 2005;19:170-3.

48. Kerbaul F, Rondelet B, Motte S, Fesler P, Hubloue I, Ewalenko $\mathrm{P}$, et al. Effects of norepinephrine and dobutamine on pressure load-induced right ventricular failure. Crit Care Med 2004;32:1035-40.

49. Taichman DB, Ornelas J, Chung L, Klinger JR, Lewis S, Mandel J, et al. Pharmacologic therapy for pulmonary arterial hypertension in adults: CHEST guideline and expert panel report. Chest 2014;146:449-75. 